\title{
A organização e o processo de trabalho da enfermagem em uma central de material
}

\author{
The organization and the process of nursing work in a material \\ centre
}

\author{
Carolina Cabral Pereira da Costa ${ }^{1}$ - Norma Valeria Dantas de Oliveira Souza ${ }^{2}$ Elias Barbosa de Oliveira ${ }^{3}$ Marcia Tereza \\ Luz Lisboa ${ }^{4}$ Manoel Luís Cardoso Vieira ${ }^{5}$ Patrícia Alves dos Santos Silva ${ }^{6}$
}

\begin{abstract}
RESUMO
Objetiva-se descrever e analisar a organização e o processo de trabalho dos trabalhadores de enfermagem da Central de Material e Esterilização de um Hospital Geral. Estudo qualitativo, desenvolvido com 34 trabalhadores de enfermagem, entre março a maio de 2013, utilizando-se a entrevista semiestruturada associada à observação não participante. Os depoimentos foram analisados à luz da Análise de Conteúdo. Evidenciou-se o cotidiano laboral do setor, com enfoque para os meandros da organização do trabalho e para a peculiaridade do processo do trabalho da enfermagem. Ficou bem delimitada a precarização das condições e dos vínculos de trabalho nesta organização e constatou-se que há entre o trabalho prescrito e o trabalho real, grande distanciamento. Conclui-se que a organização do trabalho na Central é marcada por um sistema de contratação de recursos humanos, de caráter temporário, gerando uma elevada rotatividade de trabalhadores e prejuízos para a qualidade da assistência.
\end{abstract}

Palavras-chave: Enfermagem; Saúde do Trabalhador; Esterilização.

\begin{abstract}
The aim is to describe and analyze the organization and work process of the nursing staff of Material and Sterilization Centre of a General Hospital. A qualitative study, developed with 34 nursing workers from March to May 2013, using a semi-structured interview associated with non-participant observation. The reports were analyzed according to the Content Analysis. It was evident the work routine in the industry, focusing on the intricacies of the work organization and the peculiarity of the nursing work process. It was well outlined the precarious conditions and working relations in this organization and it was found that there is between the prescribed work and real work, great distance. It concludes that the organization of work in the Centre is marked by a hiring human resources system, temporary, generating a high turnover of workers and damage to the quality of care.
\end{abstract}

Keywords: Nursing; Occupational Health; Sterilization.

${ }^{1}$ Enfermeira. Doutoranda em Enfermagem pela Universidade do Estado do Rio de Janeiro. Especialista em Enferma-gem do Trabalho e em Enfermagem em Estomaterapia. Enfermeira do Instituto Estadual de Cardiologia Aloysio de Castro e Professora do Centro Universitário Celso Lisboa. Rio de Janeiro, Brasil. E-mail: carolcuerj@hotmail.com. Autor correspondente.

${ }^{2}$ Enfermeira. Doutora em Enfermagem. Diretora e Professora Associada da Faculdade de Enfermagem da Universida-de do Estado do Rio de Janeiro. Coordenadora da PósGraduação em Enfermagem em Estomaterapia da UERJ. Pós cientista da UERJ. Rio de Janeiro, Brasil. E-mail: norval_souza@yahoo.com.br.

${ }^{3}$ Enfermeiro. Pós Doutor em Álcool e Drogas. Professor Associado de Enfermagem em Saúde Mental e Psiquiatria da Universidade do Estado do Rio de Janeiro. Professor permanente da Pós-graduação strictu sensu da UERJ. Rio de Ja-neiro, Brasil. E-mail: eliasbo@oi.com.br

${ }^{4}$ Enfermeira. Doutora em Enfermagem. Professora Associada da Escola de Enfermagem Anna Nery da Universidade Federal do Rio de Janeiro. Membro do Núcleo de Pesquisa Enfermagem e Saúde do Trabalhador e Núcleo de Pesquisa de Fundamentos do Cuidado de Enfermagem. Rio de Janeiro, Brasil. E-mail: marcialuzlisboa@gmail.com.

${ }^{5}$ Enfermeiro. Doutorando em Enfermagem pela Universidade do Estado do Rio de Janeiro. Especialista em Enferma-gem do Trabalho e em Centro Cirúrgico e Central de Material e Esterilização. Professor do Centro Universitário Celso Lisboa. Rio de Janeiro, Brasil. E-mail: mlcv22@bol.com.br.

${ }^{6}$ Enfermeira. Mestre em Enfermagem. Especialista em Enfermagem em Estomaterapia. Enfermeira da Clínica de Es-tomaterapia da Policlínica Piquet Carneiro e Professora da Universidade Estácio de Sá. Rio de Janeiro, Brasil. E-mail: papatyenf@gmail.com. 


\section{INTRODUÇÃO}

O objeto deste estudo versa sobre a organização e o processo de trabalho da enfermagem na Central de Material e Esterilização (CME).

A CME é uma unidade essencial no cenário hospitalar, sendo responsável pela recepção, expurgo, limpeza, descontaminação, preparo, esterilização, guarda e distribuição dos materiais utilizados por diversos setores na estrutura organizacional ${ }^{1}$. E, por esta razão, é um setor que destaca-se no contexto da organização hospitalar por ser uma unidade de apoio aos demais serviços assistenciais e de diagnóstico, visando assegurar a disponibilidade de materiais, com a qualidade necessária e em quantidade suficiente ao adequado funcionamento institucional, para que os clientes sejam satisfatoriamente assistidos ${ }^{2}$.

Assevera-se que esta unidade possui uma dinâmica de trabalho caracterizada por tarefas monótonas, repetitivas e fragmentadas, decorrentes do processamento de materiais, predominando o trabalho manual ${ }^{3}$. Além disso, ressaltase que a maioria das CMEs é caracterizada por sistemas de ventilação incipientes, espaços físicos diminutos e, mobiliário ergonomicamente inapropriado, entre outros aspectos que prejudicam a saúde dos trabalhadores ${ }^{4}$.

De outro modo, muitas atividades devem ser executadas com extrema atenção, devido aos riscos de acidentes, exigindo dos profissionais maior concentração e habilidade psicomotora para a sua execução. Ademais, há a demanda de elevada responsabilidade profissional acerca da segurança e qualidade da esterilização dos materiais hospitalares neste espaço de trabalho ${ }^{1}$.

Neste contexto, o processo de trabalho nas CMEs acarreta sofrimento psíquico aos trabalhadores, expressos por meio de sentimentos de abandono, agressividade, doenças psicossomáticas e mentais ${ }^{4}$.

Nesse setor, frequentemente existe um grande quantitativo de funcionários com depressão, absenteísmo, coexistindo sentimentos de insatisfação com o desprazer relacionado à ausência de um relacionamento mais efetivo com o paciente ${ }^{4}$. Acrescenta-se, ainda, o descontentamento diante da falta de reconhecimento e da valorização das atividades desses trabalhadores no contexto hospitalar e o presenteísmo no trabalho ${ }^{5}$, o qual pode ser definido pela presença do funcionário no ambiente laboral, porém, apresentando problemas físicos ou mentais, levando ao comprometimento de suas atividades laborais, pois este não produz eficaz e eficientemente ${ }^{6}$.

Neste sentido, verifica-se que este é um cenário laboral com características peculiares e complexas. 0 trabalho executado nesse ambiente é minucioso, repetitivo e requer grande atenção daqueles que o realizam; por conta disto, em alguns momentos há certa dificuldade em manter no setor um grupo de profissionais estável, estimulado e em sincronia com as tarefas à serem realizadas ${ }^{5}$.

Desta forma, é uma área que exige pessoas com formação e capacitação adequadas a execução das técnicas especializadas, além de concentração, destreza manual e atenção. Porém, o que observa-se, muitas vezes, é a inexistência de um método de dimensionamento de pessoal que tanto considere a especificidade do processo de trabalho desenvolvido no cenário, quanto possa propiciar elementos para o adequado funcionamento do setor ${ }^{7}$.

Observa-se que os trabalhadores de enfermagem lotados na CME, em geral, são aqueles que estão próximos à aposentadoria, ou seja, os mais idosos, e também aqueles com algum tipo de problema de saúde, como hipertensão arterial, lombalgias, afecções cardiovasculares, dentre outras. São encaminhados também os profissionais com algum problema de relacionamento interpessoal, além dos considerados não aptos à assistência direta ao cliente ${ }^{5}$.

É, assim, um setor que carece de investigação contínua para que seu processo de trabalho seja desvelado a fim de que estratégias de melhorias possam ser implementadas para assegurar uma excelência na execução da tarefa e garantir a saúde dos trabalhadores. Isto porque foi realizada uma busca inicial nas bases de dados da Literatura LatinoAmericana e do Caribe em Ciências da Saúde (LILACS), Scientific Electronic Library Online (SCIELO), Base de Dados de Enfermagem (BDENF) e Medical Literature Analysis and Retrieval System Online (MEDLINE), sem restrição de idioma, utilizando-se os descritores "Saúde do Trabalhador", "Enfermagem" e "Esterilização", sendo encontrados 24 artigos.

Ao fazer uma análise em relação à oferta dos textos completos destes artigos, verificou-se que apenas 13 estavam disponíveis na íntegra. Entretanto, dessas publicações, apenas 05 estiveram vinculadas à temática do presente estudo. A busca foi realizada durante o mês de julho de 2017 e não houve a determinação de um recorte temporal. Isto reforça a relevância desta pesquisa e a necessidade de serem realizadas novas investigações acerca da referida temática.

Considerando esta contextualização sobre o objeto, foi elaborada a seguinte questão norteadora: como se dá a organização e o processo de trabalho da enfermagem na Central de Material e Esterilização (CME)? A presente pesquisa propõe como objetivos: descrever e analisar a organização e o processo de trabalho dos trabalhadores de enfermagem da CME de um hospital geral.

Uma justificativa importante para a realização deste estudo ancorou-se no fato de o mesmo buscar desvendar os meandros de um espaço de trabalho da Enfermagem que vem sendo esquecido pelos gestores, tanto em termos de pesquisa quanto no que se refere à necessidade da melhoria das condições de trabalho.

Esse estudo contribui para ampliação do conhecimento produzido pela profissão, fortalecendo e consolidando o ensino, a assistência e a pesquisa relacionados à Saúde do Trabalhador, colaborando para um repensar contínuo acerca do trabalho de enfermagem nas CMEs, vislumbrando 
estratégias mais efetivas para uma organização laboral que promova e assegure o bem-estar dessa força de trabalho. Visa contribuir também para ampliar a compreensão sobre alguns dos fatores que têm causado o adoecimento físico e/ou mental dos trabalhadores de enfermagem, além de possibilitar o entendimento sobre os efeitos do trabalho na CME no corpo do trabalhador.

\section{MÉTODO}

Trata-se de uma pesquisa bibliográfica de abordagem qualitativa, do tipo descritivo-exploratório. 0 estudo foi realizado na CME de um hospital geral, situado no município do Rio de Janeiro.

Os participantes do estudo foram 34 profissionais de enfermagem (09 enfermeiras e 25 técnicos de enfermagem) que trabalhavam na referida CME. Desse quantitativo, 24 trabalhavam no serviço diurno. Cabe destacar, ainda, que 26 participantes cumpriam $30 \mathrm{~h}$ semanais na referida unidade, enquanto 08 perfaziam uma jornada de 40h. Apenas 11 trabalhadores eram servidores estatutários, o que demonstra a fragilidade de vínculos de trabalho para a maioria destes profissionais de enfermagem.

Os critérios de inclusão utilizados foram: a) tempo de atuação no cenário igual ou superior a 06 meses, pois considerou-se que esse era um período suficiente para os trabalhadores apreenderem as características da organização do trabalho e do processo laboral na CME; b) tipo de vínculo com o hospital, podendo ser servidores estatutários (profissionais concursados), contratados formalmente (CLT) ou, ainda, trabalhadores sob outra forma de contratação (contratos precários), em qualquer turno de trabalho.

Os critérios de exclusão adotados foram: a) estar de férias ou de licença de qualquer natureza durante o período de coleta de dados, b) ser residente, uma vez que a instituição possui um Programa de Residência em Enfermagem, porém os residentes passam apenas um curto período na unidade, podendo então, comprometer a percepção da organização e processo laboral devido à uma visão superficial deste trabalho.

$\mathrm{Na}$ coleta de dados, utilizou-se a entrevista individual do tipo semiestruturada, associada à observação não participante no setor, norteada por um formulário com aspectos referentes à estrutura física da CME e ao processo, e à organização laboral, os quais podem acarretar prejuízos ao processo saúde-doença dos trabalhadores de enfermagem (totalizando vinte horas de registro de campo, realizadas em dias e horários distintos).

A coleta de dados por meio de entrevista foi efetuada entre março e maio de 2013, somente após a aprovação da pesquisa pelo Comitê de Ética em Pesquisa. Ressaltase que o tempo médio de duração das entrevistas foi de 15 minutos, as quais foram gravadas por meio de um equipamento de gravador digital (MP5 player) e, posteriormente, transcritas.
Para atender as exigências éticas, a pesquisa foi aprovada pelo Comitê de Ética da instituição, obtendo o número de parecer 081.3.2012.Além disto,cada participante assinou um Termo de Consentimento Livre e Esclarecido, e preservou-se o anonimato dos participantes, identificandoos por um código alfanumérico nas descrições dos relatos (E para enfermeiros e TE para técnicos de enfermagem; a numeração seguiu a ordem cronológica das transcrições das entrevistas). Todos esses procedimentos estão em consonância com a Resolução 466/2012 do Conselho Nacional de Saúde/Ministério da Saúde.

As informações coletadas foram transcritas, analisadas e interpretadas à luz da Análise de Conteúdo ${ }^{8}$. Na categorização dos dados, seguiram-se os passos: préanálise (leitura flutuante); constituição do corpus; formulação de hipóteses e objetivos; exploração do material; e tratamento dos resultados obtidos ${ }^{8}$. Os dados coletados por meio da observação foram inseridos na análise e discussão, com o objetivo de reafirmar, enriquecer ou até mesmo de evidenciar a relação entre os discursos e a observação realizada. Assim, elaborou-se a categoria intitulada: O cotidiano laboral e as especificidades da organização do trabalho na CME.

\section{RESULTADOS}

Os resultados obtidos evidenciaram o cotidiano laboral na CME, com enfoque para os meandros da organização do trabalho e para a peculiaridade do processo do trabalho da enfermagem. Ou seja, apresenta-se a forma como o trabalho é desenvolvido na unidade, o modo operatório dos trabalhadores frente às tarefas, e a especificidade da organização prescrita e real do trabalho no referido cenário.

Os trabalhadores relataram as atividades que são desenvolvidas diuturnamente a fim de dar conta das tarefas prescritas pela organização do trabalho, conforme se verifica a seguir:

"A gente chega e recebe o plantão do enfermeiro, pega a rotina das autoclaves, das estatísticas, dos materiais das cirurgias do dia. Tem toda uma sequência especial." (E2)

“O trabalho aqui é a gente iniciar com a qualificação dos processos através dos testes de Bowie \& Dick no turno da manhã. Assim, enquanto enfermeiro, a gente faz o acompanhamento desses ciclos e, posteriormente, a incubação adequada desses resultados. Para, em seguida, iniciar as demais rotinas: o início da esterilização dos processos, conferir a escala, verificar todos os insumos se estão em falta ou não, se faltam funcionários. E se faltar, a gente vai precisar realocar outra pessoa." (E5)

Durante a observação no setor, destacou-se a função de liderança e supervisão assumida pelos enfermeiros, fato que emergiu nos discursos dos entrevistados acima. Neste sentido, para atingir a finalidade 
de seu processo de trabalho e atender às demandas do setor, o enfermeiro deve ser dotado de características que o permitam desempenhar, além da função assistencial, as funções de coordenação, técnico-administrativas e de administração de pessoal.

Os participantes destacaram o sentimento de orgulho frente à responsabilidade de suas atividades para 0 bom funcionamento do hospital e para o cuidado ao paciente. Verificou-se que, com o processo laboral por eles desenvolvido, o modo operatório com que empreendem o trabalho, estes trabalhadores contribuem para a segurança dos pacientes e dos funcionários de todo hospital, consequentemente, colaboram com a excelência do serviço hospitalar, resultando em orgulho e auto realização. As falas selecionadas a seguir evidenciam esse resultado:

“[...]então essa questão da responsabilidade é muito importante, e é muito gostoso você saber que é importante para o hospital, isto dá orgulho [...]." (TE5)

"[...] é muita responsabilidade trabalhar aqui porque lidamos com muitas coisas e às vezes a demanda é muito grande. Temos que ter muita atenção, pois qualquer distração pode levar a consequências muito negativas para a assistência e para todo mundo [...]." (TE17)

Outra situação prevalente nos discursos dos entrevistados foi a carência de recursos humanos para a realização das atividades, o que dificultava o processo laboral na CME, aumentando a sobrecarga de trabalho.

"[...] uma coisa que é importante é a falta de pessoal, porque, quando você consegue treinar bem o funcionário, ele sai. Por exemplo, este mês acaba o contrato de uma menina bem treinada que sabia fazer tudo. Porque o enfermeiro em treinamento profissional bolsista e o contratado não ficam muito tempo, já que aparecem novas oportunidades, este profissional que nós treinamos e que não tem oportunidade aqui vai embora, porque o salário é baixo, então financeiramente não compensa [...]." (E7)

“[...] aí no serviço noturno, eu tenho que ficar na esterilização, na distribuição do material cirúrgico e lá embaixo na distribuição do material clínico, eu fico com as chaves e sou eu que faço esses trabalhos todos, é muito desgastante. Tudo porque não tem pessoal suficiente [...]." (TE16)

Tal problemática é complexa, pois a inadequação de recursos humanos no setor, principalmente no serviço noturno, é uma das principais características desta organização do trabalho, já que existem aposentadorias, óbitos e licenças de funcionários, que não têm sido repostos. Observa-se a polivalência e a multifuncionalidade dos funcionários ativos, penalizando os mesmos por conta do volume de atividades e do ritmo elevado de trabalho.

Observou-se durante o período de observação, uma grande rotatividade dos trabalhadores contratados e dos enfermeiros em Treinamento Profissional Bolsista (TPB), constatando-se um quadro de funcionários efetivos cada vez menor. Ressalta-se que Enfermeiro TPB é aquele que se encontra em Treinamento Profissional, desenvolvendo suas atividades em um cenário específico. Assim, não possui um vínculo de trabalho com a instituição, sendo denominado "bolsista".

Constatou-se a insatisfação dos trabalhadores frente à precariedade dos vínculos de trabalho, uma vez que os trabalhadores contratados eram prejudicados e/ou explorados pela inexistência ou diferença de direitos trabalhistas, quando comparado aos servidores estatutários, conforme os relatos a seguir:

“[...] aqui só quem ganha bem são os estatutários, os contratados não têm direito a nada, somente o salário e olhe lá [...]." (E7)

"[...] os contratos estão todos saindo, a gente ganha mal e não têm direitos, então quando conseguimos alguma coisa melhor, a gente vai embora [...]." (TE9)

Outro resultado captado, tanto nas entrevistas quanto na observação,foram as condições inadequadas de trabalho em decorrência da insuficiência de insumos materiais que permeia tal organização laboral.

"[...] por mais que aqui a gente tenha uma gama de materiais bastante interessante, falta muito material, às vezes a nossa chefa tem que entrar com pedido de material e pedido de compra também, isso acaba comprometendo a nossa rotina [...]." (E4)

“[...] esse estresse está vinculado à falta de recursos, falta muito material, então gera problemas com outros setores que poderiam ser contornados mais rapidamente e não são [...]." (E5)

Durante a observação não participante no setor, constatou-se que a carência de materiais é um fator negativo na rotina de trabalho, uma vez que deixa os trabalhadores ainda mais susceptíveis ao surgimento do estresse ocupacional, à angústia e ao sofrimento em decorrência do trabalho, já que os mesmos desejam desenvolver as atividades da forma mais admissível, o que às vezes não é possível. Verificou-se, ainda, por meio da observação de campo, a necessidade de constantes improvisações e adaptações durante a jornada de trabalho, como a realização de alguns testes indispensáveis à monitorização dos processos na autoclave, os quais deveriam ser feitos diariamente, mas são realizados em dias intercalados, por conta da escassez de material.

Os participantes associaram a carência de materiais aos empecilhos burocráticos institucionais, uma vez que, no cenário do estudo, o processo de compra é realizado por meio de licitações, o que retarda a chegada dos insumos ao setor, prejudicando o processo de trabalho da CME.

"[...] mas tudo demora, porque tem que ter licitação, às vezes o material pedido é caro, aí eles sugerem 
outros modelos mais baratos, aí é mais demora e mais desgaste. Eu fico pensando: será que o paciente pode esperar? Será que o trabalho pode esperar? Será que não há uma outra forma de gerenciar?" (E7)

\section{DISCUSSÃO}

A Enfermagem é uma profissão dotada de inúmeras particularidades, que envolvem as relações interpessoais, condições laborais, processo e organização do trabalho, conteúdo da tarefa, dentre outras questões, resultando na forma e no meio pelo qual é desenvolvido o objeto de trabalho da profissão: o cuidado, seja direto ou indireto9.

A divisão técnica e social que permeia o trabalho de enfermagem aponta para a repartição de tarefas, responsabilidades, hierarquias e comandos ${ }^{10}$. No caso da CME estudada, o trabalho de enfermagem é dividido por duas categorias profissionais: técnico de enfermagem e enfermeiro, cada qual desenvolvendo seu papel, determinado principalmente pelo trabalho prescrito. Essas pessoas executam tarefas diferentes, porém complementares, divergindo no nível de complexidade e na cobrança da organização prescrita do trabalho ${ }^{10}$.

A maioria dessas atividades consideradas de rotina pelos trabalhadores de enfermagem encontra-se em consonância com o que é preconizado pela Resolução Colegiada $\mathrm{n}^{0} 15$, de 15 de março de $2012^{11}$, segundo a qual a CME é responsável pelo processamento de todos os artigos médico-hospitalares, desde a limpeza, a seleção, a integridade, a funcionalidade e o acondicionamento, até a distribuição desses artigos esterilizados às unidades consumidoras, a fim de garantir a realização dos procedimentos assistenciais da instituição.

Reforça-se também a função de liderança e supervisão assumida pelos enfermeiros, o que tanto emergiu nos discursos dos participantes quanto foi constatado na observação de campo. Neste sentido, para atingir a finalidade de seu processo de trabalho e atender as demandas do setor, o enfermeiro deve ser dotado de características que o permitam desempenhar funções de coordenação, técnico-administrativas e de administração de pessoal ${ }^{12}$.

O sentimento de orgulho diante da responsabilidade para com as tarefas, o hospital e os pacientes encontra-se em consonância com o que é citado pela literatura, pois a CME é um ambiente que demanda trabalho contínuo e rotineiro, que deve ser exercido com atenção, concentração e de acordo com as normas recomendadas. Desta forma, o profissional lotado nesse setor deverá ser capacitado para desempenhar suas tarefas, ser responsável e comprometido².

A carência de recursos humanos para a realização das atividades, gera sobrecarga de trabalho, uma vez que a enfermagem é uma das ocupações com alto risco de desgaste, estresse e adoecimento, pela falta de um dimensionamento adequado de recursos humanos, tanto em termos quantitativos quanto qualitativos ${ }^{13}$.
Tal problemática é conflituosa e complexa, pois a inadequação de recursos humanos no setor, principalmente no serviço noturno, é uma das principais características desta organização do trabalho, já que existem aposentadorias, óbitos e licenças de funcionários, que não têm sido repostos. Neste sentido, devido ao serviço noturno ser entendido como mais tranquilo em termos de ritmo laboral, opta-se por reduzir o número de funcionários do período da noite, gerando sobrecarga para aqueles que permanecem trabalhando ${ }^{14}$. Observa-se a polivalência e a multifuncionalidade dos funcionários ativos, penalizandoos por conta do volume de atividades e do ritmo elevado de trabalho.

Há também uma grande rotatividade dos trabalhadores contratados e dos enfermeiros TPB, observando-se, por conseguinte, um quadro de funcionários efetivos cada vez menor, mesmo com dois concursos públicos vigentes, um para técnicos de enfermagem e outro para enfermeiros. Ou seja, o déficit de pessoal é tão elevado que, mesmo com algumas reposições de recursos humanos oriundos desses concursos, tal quantitativo não é suficiente para que o trabalho se desenvolva sem maiores sobrecargas psicofísicas para os que estão ativos na escala de serviço.

Outro ponto a ser discutido é que os profissionais contratados somente podem permanecer na instituição por um período máximo de cinco anos, o que já resulta em rotatividade de pessoal. Porém, muitos pedem demissão antes de completar esse período, devido aos baixos salários e à precarização das condições de trabalho ${ }^{14}$.

Tal fato gera admissões frequentes de profissionais e a necessidade de capacitação e treinamento do pessoal recém-contratado. Neste sentido, até que esses trabalhadores apreendam $\mathrm{o}$ processo de trabalho $\mathrm{e}$ se adaptem a especificidade da organização laboral, evidenciam-se custos psicofísicos para os profissionais que estão na escala de serviço, devido à sobrecarga de tarefas ${ }^{14}$.

$\mathrm{Na}$ instituição investigada, a insatisfação dos funcionários frente à precariedade dos vínculos de trabalho é relevante, uma vez que os profissionais de enfermagem contratados e os TPB recebem um salário muito aquém do recebido pelos estatutários, e não têm assegurados os direitos celetistas, como férias, Fundo de Garantia por Tempo de Serviço (FGTS) e outras garantias previstas pela Consolidação das Leis Trabalhistas (CLT), destacando-se ainda a inexistência de outras vantagens inerentes aos trabalhadores estatutários, como as licenças especiais e a própria estabilidade no trabalho.

Neste sentido, fica bem marcada a precarização das condições de trabalho, a qual vem se instituindo desde 0 advento do modelo neoliberal ${ }^{15}$. No entanto, os profissionais, celetistas ou não, executam as mesmas tarefas, estando igualmente expostos aos riscos oriundos da atividade laborativa. A contratação temporária no SUS configura-se como trabalho precário, na medida em que não garante os direitos trabalhistas e previdenciários consagrados em lei. 
Há, em todo mundo, inúmeros trabalhadores cujo trabalho pode ser caracterizado como precário, se considerados os efeitos para a saúde e para a qualidade de vida ${ }^{16}$.

Também foi relatado a insuficiência de recursos materiais, constatando-se como uma característica da organização do trabalho, demonstrando que há entre o trabalho prescrito e o trabalho real grande distanciamento, verificado quando os participantes referiram à carência de recursos materiais, como um afastamento do prescrito. Sendo assim, preconiza-se a necessidade de dispor de insumos hospitalares para prestar cuidados aos clientes; porém, a organização do trabalho não disponibiliza esses insumos como deveria. Tal situação interfere na dinâmica de trabalho de enfermagem e, por sua vez, repercute negativamente na saúde dos trabalhadores².

A carência de materiais é um fator negativo na rotina de trabalho, uma vez que deixa os trabalhadores ainda mais susceptíveis ao surgimento do estresse ocupacional, à angústia e ao sofrimento em decorrência do trabalho, já que os mesmos desejam desenvolver as atividades como preconizado pelos manuais, livros e pela lei do exercício profissional. Neste contexto, o processo de trabalho é permeado por ajustes, regulações, adaptações e improvisos, a fim de que o trabalhador possa dar conta da tarefa. Percebe-se, então, uma organização do trabalho que pouco privilegia o prescrito, impelindo o trabalhador à modificar seu modo operatório, que nem sempre caracteriza-se como o ideal para o objeto de seu trabalho, violentando psiquicamente o trabalhador e abrindo espaço para se instituir doenças relacionadas ao trabalho ${ }^{17}$.

Tem-se discutido que os atuais sentimentos de frustração e ansiedade dos trabalhadores são devidos à falta de material, o que exige uma maior capacidade de improvisação por parte desses trabalhadores para a realização de procedimentos, deixando-os insatisfeitos em relação à assistência prestada ao paciente. Esses elementos somados podem desencadear o sofrimento no cotidiano laboral ${ }^{18}$.

A aquisição de materiais em instituições públicas segue a Lei 8.666/1993 ${ }^{19}$, que norteia as licitações. Assim, torna-se necessário as instituições públicas respeitarem rigidamente as normas legais que regulamentam esses processos licitatórios e os detalhes do procedimento, considerando a importância de existir um controle ao adquirir materiais para uma organização. Porém, essas exigências, em muitos casos, tornam vagaroso o processo de aquisição de materiais e demandam um tempo maior de espera pelo produto ${ }^{20}$.

A morosidade nos processos administrativos verificada nos serviços de saúde é apontada como um problema crônico, gerando excessiva burocracia, apresentando serviços que não satisfazem os trabalhadores. Neste sentido, a escassez de alguns produtos, dentro de um hospital, é talvez um dos pontos que mais afligem os profissionais envolvidos com o processo gerencial e assistencial, pois a escassez implica, muitas vezes, na interrupção da assistência, levando à vivência de situações danosas e estressantes para o cliente, à família e os profissionais ${ }^{20}$.

O enfermeiro pode e deve participar das comissões de licitação, dos grupos de assessorias de compra e da emissão de pareceres técnicos, melhorando a qualidade e a quantidade dos produtos. Porém, esses profissionais não conseguem modificar a vagarosidade do processo, já que isso fica fora de suas competências profissionais, apesar de entendermos que por organização política da classe poderia-se modificar essa morosidade nas licitações.

Por outro lado, cabe mais uma reflexão, pois, se os gerentes são obrigados por lei a fazer tal processo licitatório para compra de materiais e equipamentos, há então a necessidade de elaborar um competente planejamento para garantir o provimento de insumos hospitalares para o semestre ou mesmo para o ano, a fim de evitar falta de materiais imprescindíveis para a assistência. Apesar de todos os esforços dos gerentes da instituição no que tange à um planejamento prévio para a previsão dos materiais, há pouco investimento governamental para que se tenha os recursos necessários para dar continuidade ao serviço até a conclusão dos processos licitatórios no tempo adequado.

Neste sentido, a competência gerencial exige o desenvolvimento de habilidades operacionais e a capacidade de o gerente lidar com as forças de dentro e fora das organizações por meio do desenvolvimento de atitudes, valores e visões de mundo ${ }^{20}$. Além disso, torna-se necessária a constante capacitação e atualização desses gestores para atuarem junto aos processos de licitação. Ressalta-se que, no cenário do estudo, existe uma equipe, com representatividade do profissional enfermeiro que realiza um trabalho sustentado por informações repassadas pelos trabalhadores de enfermagem.

Assim, acredita-se que o envolvimento dos trabalhadores nesse processo é de vital importância à estruturação do trabalho. O comprometimento da Enfermagem com a análise dos materiais, o controle, o uso racional, o acompanhamento da eficácia dos produtos e a sensibilização desses profissionais para o envolvimento nessa política passa a ser um impulsionador para o alcance da qualidade 20 .

\section{CONCLUSÃO}

Concluiu-se que a organização do trabalho na CME investigada é marcada por um sistema de contratação de recursos humanos, de caráter temporário, o que acarreta uma elevada rotatividade de trabalhadores e prejuízos na qualidade e na dinâmica da assistência, uma vez que se torna necessário constantes treinamentos e, muitas vezes, uma capacitação do pessoal recém-admitido.

Além disso, ficou evidente que a precarização dos vínculos laborais, compromete não apenas a saúde das pessoas que ali trabalham, mas também a assistência prestada.Sugere-se a participação efetiva dos trabalhadores 
nas lutas políticas que envolvem a classe e a área da saúde, buscando condições dignas de trabalho. Tal configuração da organização do trabalho hospitalar está vinculada à crise no sistema de saúde brasileiro, especialmente nas instituições públicas.

Torna-se fundamental incentivar e fomentar a capacidade crítica e reflexiva dos trabalhadores de enfermagem, ajudando-os a pensar estratégias de melhorias das condições de trabalho, fortalecendo-os na implementação de estratégias de melhoria do cenário no qual desenvolvem as atividades laborais.

Recomenda-se, ainda, que os docentes de enfermagem desenvolvam um ensino relacionado à CME mais atraente e mais divulgado, a fim de valorizar o conhecimento de sua complexidade e o rico campo de seu trabalho. Sugerese também que sejam viabilizadas condutas assertivas para sensibilizar os gestores e trabalhadores para a problemática e para a complexa e desgastante situação em que encontram-se os trabalhadores de enfermagem deste cenário estudado e de tantas outras Centrais de Materiais.

Apresenta-se como uma limitação para o presente estudo o fato de se ter apontado características da organização e do processo de trabalho de enfermagem hospitalar relacionadas à apenas uma instituição pública. Assim, sugere-se que novos estudos sejam realizados, inclusive, em outros hospitais da rede pública, além de pesquisas comparativas entre a realidade das instituições públicas e privadas e as repercussões para a saúde dos trabalhadores de enfermagem.

\section{REFERÊNCIAS}

1. Ascari RA, Vidori J, Moretti CA, Perin EMF, Silva OM, Buss E. O processo de esterilização de materiais em serviços de saúde: uma revisão integrativa. Braz J Surg Clin Res. 2013; 4: 33-8.

2. Ouriques CM, Machado ME. Enfermagem no processo de esterilização de materiais. Texto contexto - enferm. 2013. Sep; 22(3): 695-703.

3. Gouveia MTO, Oliveira VC, Lira IMS. Ergonomic risks in a Material and Sterilization Center. Rev Enferm UFPI. 2016. JulSet; 5 (3):42-47.

4. Costa CCP, Souza NVDO, Pires AS. Profile of workers of a material and sterilization: an analysis of social and professional characteristics. J. res.: fundam. care. online 2016. jan./mar. 8(1):3633-3645.

5. Pezzi MCS, Leite JL. Investigação em Central de Material e Esterilização utilizando a Teoria Fundamentada em Dados. Rev. bras. enferm. 2010; 63(3):391-6.

6. Johns G. Presenteeism in the workplace: a review and research agenda. J. Organiz. Behavior. 2010; 31 (4): 519-542.

7. Costa JA, Fugulin FMT. Nursing activities in central supply and sterilization: a contribution to personal design. Acta Paul. Enferm. 2011; 24(2): 249-256.

8. Bardin L. Análise de conteúdo. $3^{a}$ ed. Lisboa: Edições 70, 2011.

9. Pires, DEP. Transformações necessárias para o avanço da Enfermagem como ciência do cuidar. Rev. bras. enferm. 2013. Sep; 66(spe): 39-44.
10. Thofehrn MB, Amestoy SC, Porto AR, Arrieiral ICO, Dal Pai D. A dimensão da subjetividade no processo de trabalho de enfermagem. Rev. enferm. saúde. 2011. Jan-Mar; 1(1): 190-8.

11. Brasil. Ministério da Saúde. Agência Nacional de Vigilância Sanitária. RDC $n^{\circ} 15$, de 15 de março de 2012. Dispõe sobre requisitos de boas práticas para o processamento de produtos para saúde e dá outras providências. Brasília (DF): MS; 2012.

12. Almeida ML, Segui MLH, Bernadino E, Méier MJ, Peres AM. Direção ou coordenação? Repensando a representatividade institucional da enfermagem. Rev. bras. enferm. 2011. 64(3):521-6.

13. Penedo RM, Spiri WC. Meaning of the Systematization of Nursing Care for nurse managers. Acta Paul Enferm. 2014; 27(1):86-92.

14. Cechin P, Freitas HMB de, Itha $S$ et al. Changes experienced by nursing professionals double workday. Nurs UFPE on line., Recife, 8(11):3855-61, Nov., 2014.

15. Gonçalves FGA, Leite GFP, Souza NVDO et al. The neoliberal model and its implications for work and the worker of nursing. J Nurs UFPE on line., Recife, 2013. Nov; 7(11):6352-9.

16. Brotto TCA, Dalbello-Araujo M. É inerente ao trabalho em saúde o adoecimento de seu trabalhador? Rev. bras. Saúde ocup., São Paulo, 2012.37 (126): 290-305.

17. Oliveira EB, Pinel JS, Gonçalves JBA, Diniz DB. Nursing work in hospital emergency units - psychosocial risks: a descriptive study. Online braz j nurs [Internet]. 2013. March [Cited 2016 Sept 28]; 12 (1): 73-88.

18. Souza NVDO, Santos DM, Ramos EL, Anunciação CT, Thiengo PCS, Fernandes MC. Repercussões psicofísicas na saúde dos enfermeiros da adaptação e improvisação de materiais hospitalares. Esc. Anna Nery Rev Enferm. 2010. 14(2):236-43.

19. Brasil. Lei n. ${ }^{\circ} 8.666$, de 21 de junho de 1993. Regulamenta o art. 37, inciso XXI da Constituição Federal, institui normas para licitações e contratos da administração pública e dá outras providências. Diário Oficial da República Federativa do Brasil, 22 Jun 1993.

20. Garcia SD, Haddad MCL, Dellaroza MSG, Costa DB, Miranda JM. Gestão de material médico-hospitalar e o processo de trabalho em um hospital público. Rev. bras. enferm. 2012 MarAbr; 65(2):339-46. 